\title{
Contributions of Hepatocytes and Bile Ductular Cells in Ductular Reactions and Remodeling of the Biliary System after Chronic Liver Injury
}

\author{
Yasuharu Nagahama, ${ }^{\dagger}$ Masayuki Sone, ${ }^{\dagger} \mathrm{Xi}$ Chen, ${ }^{*}$ Yoko Okada, ${ }^{*}$ Masahiro Yamamoto, ${ }^{*}$ Bing Xin, ${ }^{*}$ Yasuhiro Matsuo, * \\ Mikiko Komatsu, ${ }^{*}$ Akira Suzuki, ${ }^{\ddagger}$ Katsuhiko Enomoto, ${ }^{\S}$ and Yuji Nishikawa*
}

\begin{abstract}
From the Division of Tumor Pathology, ${ }^{*}$ Department of Pathology, Asahikawa Medical University, Asahikawa; the Fujii Memorial Research Institute, ${ }^{\dagger}$ Otsuka Pharmaceutical Co., Ltd., Otsu; the Division of Embryonic and Genetic Engineering, ${ }^{\ddagger}$ Medical Institute of Bioregulation, Kyushu University, Fukuoka; and the Department of Pathology, ${ }^{\S}$ Akita Red Cross Hospital, Akita, Japan
\end{abstract}

CME Accreditation Statement: This activity ("ASIP 2014 AJP CME Program in Pathogenesis") has been planned and implemented in accordance with the Essential Areas and policies of the Accreditation Council for Continuing Medical Education (ACCME) through the joint sponsorship of the American Society for Clinical Pathology (ASCP) and the American Society for Investigative Pathology (ASIP). ASCP is accredited by the ACCME to provide continuing medical education for physicians.

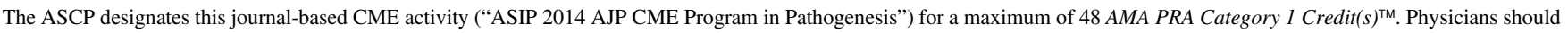
only claim credit commensurate with the extent of their participation in the activity.

CME Disclosures: The authors of this article and the planning committee members and staff have no relevant financial relationships with commercial interests to disclose.

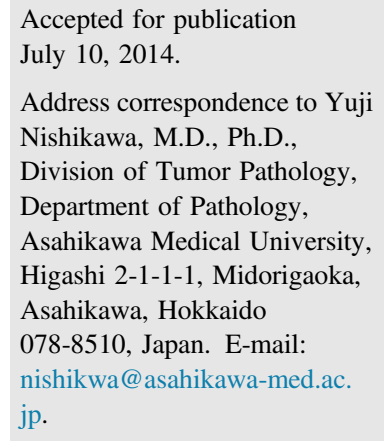

Chronic liver diseases are often complicated by ductular reaction, which is a progressive increase in bile ductular structures. ${ }^{1,2}$ Ductular reaction is closely associated with liver fibrosis and thus is an important tissue alteration to examine as a therapeutic target. ${ }^{3}$ However, the cellular origins of ductular reaction remain elusive. Experimental studies using rodents have suggested that hepatic stem-progenitor cells or transit-

\begin{abstract}
Mature hepatocytes are suggested to possess a capacity for bile ductular transdifferentiation, but whether and how hepatocytes contribute to ductular reaction in chronic liver diseases has not been elucidated. We examined whether mouse hepatocytes can transdifferentiate into bile ductular cells in vitro, using a threedimensional collagen gel culture method, and in vivo, using a liver repopulation model in which $\beta$ galactosidase-positive hepatocytes from $A l b$-Cre $\times$ ROSA26R mice were transplanted into the liver of wild-type mice. We further examined the relative contribution of intrinsic hepatocytes in ductular reaction in a hepatocyte lineage-tracing model using $M x 1$-Cre $\times$ ROSA26R mice treated with polyinosinic-polycytidylic acid. Within collagen gels, hepatocytes exhibited branching morphogenesis associated with the emergence of bile duct-like phenotype. In the liver repopulation model, many $\beta$-galactosidasepositive, hepatocyte-derived bile ductular structures were identified; these markedly increased after liver injury. In Mx1-Cre $\times$ ROSA26R mice, relatively minor but significant contributions of hepatocyte-derived bile ductules were observed in both periportal and centrilobular ductular reaction. As the centrilobular ductular reaction progressed, the portal ducts or ductules migrated toward the injured area and joined with hepatocyte-derived ductules, leaving the portal tract without biliary structures. We conclude that hepatocytes and bile ducts or ductules are important sources of ductular reaction and that the intrahepatic biliary system undergoes remarkable remodeling in response to chronic liver injury. (Am J Pathol 2014, 184: 3001-3012; http://dx.doi.org/10.1016/ j.ajpath.2014.07.005)
\end{abstract}

amplifying cells, which are believed to reside at the boundary of hepatocytes and the canals of Hering (ie, bile ductules), can proliferate into ductular shapes and eventually contribute to

Supported by Ministry of Education, Culture, Sports, Science, and Technology of Japan grants 18590362, 21590426, and 24390092 (Y.N.).

Disclosures: None declared. 
regeneration when the proliferation of hepatocytes is compromised. ${ }^{4}$ However, the periportal liver stem-cell niche is gradually coming to be recognized as more complex and involving other cell types, including bile ductular cells and periportal hepatocytes. ${ }^{5}$ Although ductular reaction typically occurs in the periportal area, it may also occur in the centrilobular area, where no biliary cells or stem-progenitor cells are present. ${ }^{6}$ Furthermore, bile duct-specific cytokeratins have been detected in damaged hepatocytes in the centrilobular area in alcoholic liver disease. ${ }^{7}$ Such observations raise the possibility that, in some types of ductular reaction, ductular transdifferentiation of mature hepatocytes might be involved. ${ }^{1,6}$

Our previous studies showed that mature rat hepatocytes can transdifferentiate into bile ductular cells when cultured within a type-I collagen gel matrix, ${ }^{8-10}$ and similar phenotypic plasticity of hepatocytes has been described by other investigators. ${ }^{11,12}$ Furthermore, we have recently demonstrated that, under modulated culture conditions, rat hepatocytes can recover their original phenotype after bile ductular transdifferentiation. ${ }^{13}$ This suggests that hepatocytic and bile ductular phenotypes are mutually reversible.

Whether mature hepatocytes can transdifferentiate into bile duct or ductular cells (hereafter, duct/ductular cells) in vivo has been a matter of debate. In a liver repopulation model using fumarylacetoacetate hydrolase-deficient mice, transplanted and repopulated hepatocytes did not substantially contribute to the ductular reaction induced by a diet with 3,5-diethoxycarbonyl-1,4-dihydrocollidine (DDC). ${ }^{14}$ In a hepatocyte lineage-tracing study using an adenoassociated virus vector in mice, hepatocytes did not change their phenotype in the presence of various type of liver injury, including those induced by a DDC diet or bile duct ligation (BDL), or during liver homeostasis. ${ }^{15}$ More recently, however, a similar lineage-tracing study demonstrated that hepatocytes can significantly participate in the generation of new ductules in the presence of liver injury induced by a DDC diet and to a lesser degree in the presence of injury induced by BDL. ${ }^{16}$ Furthermore, in a study using permanent labeling of hepatocytes and bile-duct cells with cell type-specific reporters, the centrilobular ductular reaction induced by thioacetamide (TAA) was derived almost entirely from hepatocytes, and not from bile ducts or ductules. ${ }^{17}$ Given the disparate findings in the literature regarding phenotypic plasticity of hepatocytes, it is necessary to scrutinize the cellular origins of various types of ductular reactions by rigorous pathological examination in appropriate hepatocyte lineage-tracing systems.

In the present study, we first examined and confirmed that the phenotype of mature mouse hepatocytes is also malleable when cultured within a three-dimensional collagen gel matrix. We then attempted to demonstrate that hepatocytes are capable of changing their phenotype to bile duct/ductular cells in the injured liver, by tracing intrahepatically transplanted $\beta$-galactosidase-positive $\left(\beta-\right.$ gal $\left.^{+}\right)$hepatocytes. Furthermore, the extent of the contribution of ductular transdifferentiation of hepatocytes in the ductular reaction of various types of liver injury was examined in a hepatocyte lineage-tracing system using Mxl-Cre mice. Our results demonstrate that hepatocytes can indeed transdifferentiate into bile duct/ductular cells and thus contribute to periportal and centrilobular ductular reactions, and that the existing bile duct/ductular system exhibits a profound remodeling capacity.

\section{Materials and Methods}

\section{Animals}

C57BL/6Jcl mice (CLEA Japan, Tokyo, Japan), B6.Cg$\mathrm{Tg}($ Alb-Cre) $21 \mathrm{Mgn} / \mathrm{J}$ mice (Alb-Cre; Jackson Laboratory, Bar Harbor, ME), B6.Cg-Tg(Mxl-Cre) $1 \mathrm{Cgn} / \mathrm{J}$ mice $(M x l$ Cre; Jackson Laboratory), ${ }^{18}$ and ROSA26R mice (provided by Dr. Philippe Soriano, Fred Hutchinson Cancer Research Center, Seattle, WA) ${ }^{19}$ were used in this study. The protocols for animal experimentation were approved by the Animal Research Committee, Asahikawa Medical University, and all animal experiments adhered to the criteria outlined in the current edition of the Guide for the Care and Use of Laboratory Animals. ${ }^{20}$

\section{Three-Dimensional Culture of Hepatocytes}

Centrilobular hepatocytes were isolated from the liver of adult C57BL/6Jcl mice (8 to 20 weeks old) by a digitonincollagenase perfusion technique ${ }^{21}$ (Supplemental Figure S1). We performed a three-dimensional collagen gel culture of mouse hepatocytes, as described previously ${ }^{9,22}$ (Supplemental Figure S2). After the cells were embedded within the collagen gels, spheroidal aggregates were cultured in Williams' medium E supplemented with $10 \mathrm{mmol} / \mathrm{L}$ nicotinamide, $10 \%$ fetal bovine serum, $10 \mathrm{ng} / \mathrm{mL}$ epidermal growth factor, $10^{-7}$ $\mathrm{mol} / \mathrm{L}$ insulin, $10^{-7} \mathrm{~mol} / \mathrm{L}$ dexamethasone, and $10 \mathrm{ng} / \mathrm{mL}$ tumor necrosis factor- $\alpha$ (TNF- $\alpha$ ) (PeproTech, Rocky Hill, NJ).

After completion of culture, the gels were washed three times with phosphate-buffered saline and then were either snap-frozen for biochemical analyses or fixed in $10 \%$ buffered formalin, embedded in paraffin, sectioned, and stained with hematoxylin and eosin (H\&E) or subjected to immunocytochemistry.

\section{In Vivo Lineage Tracing of Hepatocytes}

For lineage tracing of adult hepatocytes, we applied two models: a liver repopulation model and a hepatocytespecific labeling model using Mxl-Cre $\times$ ROSA26R mice treated with polyinosinic-polycytidylic acid [poly(I:C)].

\section{Liver Repopulation Model}

Adult C57BL/6Jcl mice were treated repeatedly with $60 \mathrm{mg} / \mathrm{kg}$ retrorsine i.p. (once weekly for 5 weeks) to inhibit the proliferative capacity of hepatocytes. The mice were then subjected to a $70 \%$ partial hepatectomy; after 24 hours, $\beta$-gal ${ }^{+}$hepatocytes, freshly isolated from adult $A l b$-Cre $\times$ ROSA26R by the digitonin-collagenase perfusion method, were transplanted 
into the spleen $\left(0.5\right.$ to $1 \times 10^{6}$ cells per animal). ${ }^{23}$ The mice were subjected to chronic liver injury induced either by feeding with a $0.1 \%$ DDC diet for 4 weeks or by administration of $1 \mathrm{~mL} / \mathrm{kg} \mathrm{CCl}_{4}$ s.c. (three times per week) for 8 weeks.

Hepatocyte-Specific Labeling in Mx1-Cre $\times$ R0SA26R Mice Male Mxl-Cre $\times$ ROSA26R mice ( 8 to 12 weeks old) were each injected intraperitoneally with $250 \mu \mathrm{g}$ of poly(I:C) (InvivoGen, San Diego, CA), three times at 2-day intervals. This dose of poly(I:C) injection caused no apparent organ damage, as assessed by histological studies (data not shown). At 3 days after the last poly(I:C) administration, the mice were injected with $1 \mathrm{~mL} / \mathrm{kg} \mathrm{CCl}_{4}$ s.c., three times per week for 8,11 , and 20 weeks or with $100 \mathrm{mg} / \mathrm{kg}$ TAA i.p. (SigmaAldrich, St. Louis, MO), three times per week for 21 weeks to induce ductular reaction in the centrilobular area and were fed a $0.1 \%$ DDC diet for 4 weeks. In addition, the mice were subjected to BDL for 14 days and administration of $40 \mathrm{mg} /$ $\mathrm{kg}$ 4,4'-diaminodiphenylmethane (DAPM) i.p. (Kanto Chemical, Tokyo, Japan), at 5-day intervals for 4 weeks.

\section{RT-qPCR Analysis}

Total RNA from cells and tissues was extracted and subjected to quantitative real-time RT-PCR (RT-qPCR) analysis for mRNA expression of various hepatocytic, bile duct/ductular, and hepatoblastic markers, as well as several proteins involved in tissue remodeling. The reactions were performed in duplicate, and the mRNA levels were normalized to glyceraldehyde 3-phosphate dehydrogenase (Gapdh) as a housekeeping gene. The specific primers used were as follows: albumin $(A l b)$, forward $5^{\prime}$ TTGCCAAGTACATGTGTGAA- ${ }^{\prime}$ and reverse 5'-GGCTCTTCTACAAGAGGCTG-3'; cytokeratin 19 (Krt19), forward $5^{\prime}$-GACTTCCTATAGCTATCGCC- $3^{\prime}$ and reverse $5^{\prime}$-AGTAGGAGGCGAGACGATCA-3'; delta-like 1 (Dlk1), forward 5' ATGTCTGCAGGTGCCATGTTG-3' and reverse $5^{\prime}$-GGCTTGCACAGACACTCGAAG-3'; glucose 6-phosphatase (G6pc), forward 5'-TGTCTGTGATTGCTGACCTG-3' and reverse 5'-AAAGTGAGCAGCAAGGTAGA-3'; hepatocyte nuclear factor-4 $\alpha(H n f 4 a)$, forward $5^{\prime}$-GGCATGGATATGGCCGACTAC- $3^{\prime}$ and reverse $5^{\prime}$-GACAGCTTCCTTCTTCATGCC-3'; secreted phosphoprotein 1 (alias osteopontin) (Sppl), forward 5'-GAGGAGAAGCTTTACAGCCT-3' and reverse 5'-AAGTGTCTGCTTGTGTACTA-3'; phosphoenolpyruvate carboxykinase (Pepck), forward $5^{\prime}$-CCCAAGAGCAGAGAGACACA- $3^{\prime}$ and reverse 5'-GTAGTGAGTTCCCACCATAT-3'; Sox9, forward 5'-TGCAGCACAAGAAAGACCAC- $3^{\prime}$ and reverse 5'-TCTCAATGTTGGAGATGACG-3'; tyrosine aminotransferase (Tat), forward 5'-ACAGCTTGTCTCGTGGTCAAC- $3^{\prime}$ and reverse 5'-TAAGGTACATGGCTCCAGATG-3'; transthyretin (Ttr), forward 5'-GAGTAGAACTGGACACCAAATC- $3^{\prime}$ and reverse 5'-AGAATGCTTCACGGCATCTTCC-3'; Gapdh mRNA, forward 5'-ACCACAGTCCATGCCATCAC- $3^{\prime}$ and reverse $5^{\prime}$-TCCACCACCCTGTTGCTGTA-3'. We used TaqMan (Life
Technologies, Carlsbad, CA) gene expression assays for analysis of mRNA expression for S100 calcium-binding protein A4 (S100a4), matrix metallopeptidase-2 (Mmp2), matrix metallopeptidase-9 (Mmp9), TIMP metallopeptidase inhibitor 1 (Timp1), TIMP metallopeptidase inhibitor 3 (Timp3), and TNF- $\alpha$ (Tnfa).

\section{Western Blot Analysis}

Protein samples ( $25 \mu \mathrm{g}$ protein per lane) were subjected to SDS-PAGE and then were transferred to polyvinylidene difluoride membranes. The primary antibodies used were anti-albumin (Nordic Immunological Laboratories, Tilburg, The Netherlands), anti-HNF-4 $\alpha$ (K9218; Perseus Proteomics, Tokyo, Japan), anti-CK19 (kind gift of Dr. Atsushi Miyajima, University of Tokyo, Tokyo, Japan), anti-SRY (sex determining region Y)-box 9 (Sox9) (EMD Millipore, Billerica, MA), and anti- $\beta$-actin (Novus Biologicals, Littleton, $\mathrm{CO}$ ).

\section{Microscopical Analyses}

Livers were perfused with $4 \%$ paraformaldehyde and soaked in $30 \%$ sucrose in phosphate-buffered saline overnight at $4^{\circ} \mathrm{C}$. Frozen and paraffin-embedded sections $(4 \mu \mathrm{m}$ thick) were then prepared. In some experiments, to identify the portal veins and to visualize the biliary system in tissue sections of cirrhotic liver, India ink (approximately 100 $\mu \mathrm{L}$ ) was injected directly into the portal trunk and common bile duct, respectively, and fractions of the liver tissues were cut and immersion-fixed with $4 \%$ paraformaldehyde. In addition, to obtain images of the three-dimensional architecture of the bile ducts or ductules and blood vessels, 1mm-thick slices of the fixed liver, in which the biliary system and portal vein were engorged with India ink and vermilion ink, respectively, were rendered transparent with an aqueous clearing reagent (SCALEVIEW-A2; Olympus, Tokyo, Japan) and then examined under an inverted microscope.

For $\beta$-gal histochemistry, frozen sections were rinsed in phosphate-buffered saline and reacted with X-Gal solution [1 $\mathrm{mg} / \mathrm{mL}$ 5-bromo-4-chloro-3-indolyl- $\beta$-D-galactopyranoside (X-Gal; Sigma-Aldrich), $5 \mathrm{mmol} / \mathrm{L}$ potassium ferrocyanide, and $5 \mathrm{mmol} / \mathrm{L}$ potassium ferricyanide] at $37^{\circ} \mathrm{C}$ overnight.

Immunocytochemical and immunohistochemical analyses were performed using either the peroxidase or alkaline phosphatase method after antigen retrieval using target retrieval solution, pH 6.0 (Dako, Carpinteria, CA). Several different chromogens were used: 3,3'-diaminobenzidine tetrahydrochloride (brown; Vector Laboratories, Burlingame, CA), 3amino-9-ethylcarbazole (reddish brown; Dako), Histogreen (green; Linaris Biologische Produkte, Dossenheim, Germany), and New Fuchsin (red; Nichirei Biosciences, Tokyo, Japan). The following antibodies were used: anti-HNF-4 $\alpha$ (P1) (Perseus Proteomics), anti-Sox9 (EMD Millipore), anti-CK19 
(gift of Dr. Atsushi Miyajima), anti-EpCAM (Novus Biologicals), anti-desmin (Abcam, Cambridge, UK), anti-F4/80 (AbD Serotec, Düsseldorf, Germany; Raleigh, NC), antiLYVE-1 (Abcam), and anti-phospho-histone H3 (Cell Signaling Technology, Danvers, MA).

For quantification analyses, the numbers of bile duct/ ductular structures or cells were counted on 50 photographs of each liver sample imaged with a $40 \times$ objective.

\section{Statistical Analysis}

Statistical analyses were performed using Student's $t$-test or analysis of variance on more than three independent experiments or animals.

\section{Results}

\section{Branching Morphogenesis with Emergence of} Expression of Bile Duct-Ductular Differentiation Markers in Cultured Mouse Hepatocytes

We first examined whether adult hepatocytes can transdifferentiate into bile ductular cells in mouse, as was previously shown in rat experiments. ${ }^{8,9}$ To avoid possible contamination of bile duct/ductular cells and the putative hepatic stemprogenitor cells, we selectively isolated hepatocytes from the centrilobular zone (Supplemental Figure S1). When spheroidal aggregates of hepatocytes were embedded and cultured within collagen gels (Figure 1A and Supplemental Figure S2), the hepatocytes soon migrated into the gels and formed spiny processes, and after 5 days demonstrated branching morphogenesis with scattered luminal structures that was markedly enhanced by TNF- $\alpha$ (Figure 1A). These morphological changes were associated with a dramatic decrease in the mRNA expression of Alb, Ttr, Hnf4a (Figure 1B), Tat, G6pc, and Pepck (Supplemental Figure S3), especially in the presence of TNF- $\alpha$, which suggests the loss of hepatocytic differentiation. By contrast, the expression of mRNAs relevant to bile duct differentiation emerged, such as Krt19, Sox9 (Figure 1B), and Spp1 (encoding osteopontin) (Supplemental Figure S3). The mRNA expression of $D l k 1$, a marker for hepatoblasts, was not detectable during the entire culture period (Figure 1B), suggesting that the phenotypic change might be transdifferentiation rather than dedifferentiation.

Western blot analysis showed that albumin expression was relatively well preserved (but was decreased when cells were treated with $\mathrm{TNF}-\alpha$ ), whereas $\mathrm{HNF}-4 \alpha$ expression rapidly declined in culture (Figure 2A). Protein expression
A
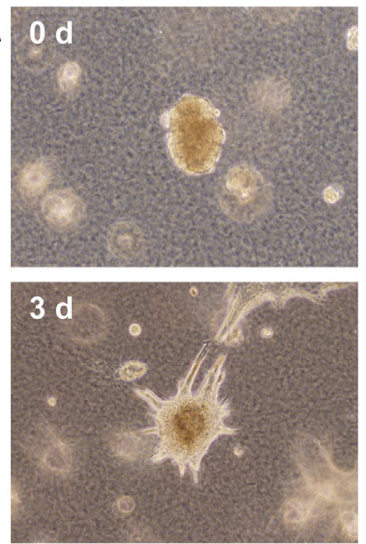

B

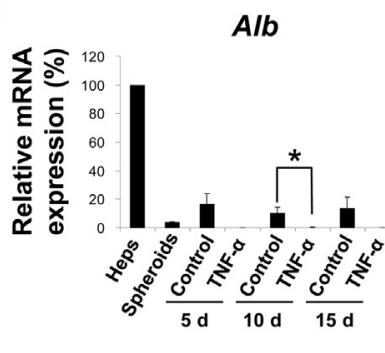

Krt19

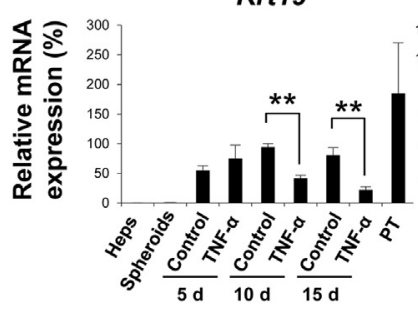

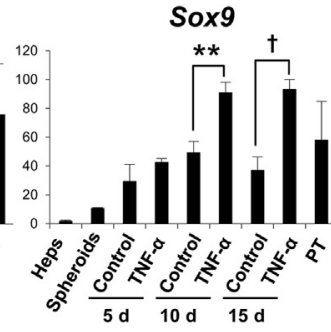
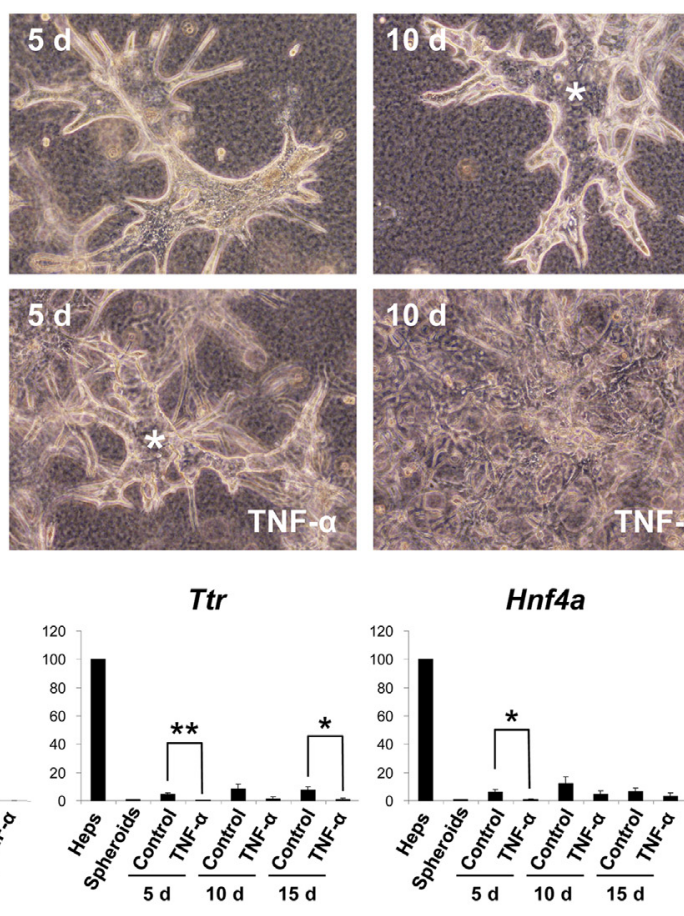

Dlk1

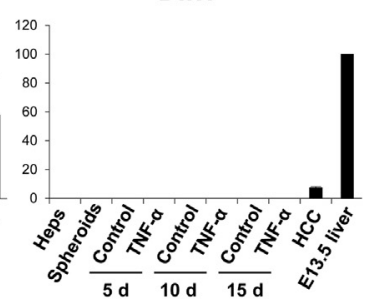

Figure 1 Branching morphogenesis of mouse hepatocytes with the appearance of the bile ductular phenotype in collagen gel culture. A: Representative phase-contrast microscopy images (10x objective) of hepatocytic spheroids immediately after embedding within a collagen gel matrix ( 0 day) and cultured for 3,5 , and 10 days in the absence or presence of $10 \mathrm{ng} / \mathrm{mL}$ TNF- $\alpha$. Note luminal structures (asterisks). B: RT-qPCR analysis for mRNA expression of various genes in freshly isolated hepatocytes, spheroids, and those cultured within collagen gels for 5, 10, and 15 days. Total RNA extracted from normal portal tissues $(n=4)$, diethylnitrosamine-induced hepatocellular carcinoma $(n=3)$, and E13.5 fetal liver $(n=3)$ were used as positive controls for bile duct-specific genes (Krt19 and Sox9) and Dlk1. Data are expressed as means \pm SEM of three independent experiments. ${ }^{*} P<0.05,{ }^{*} P<0.01$, and ${ }^{\dagger} P<0.005$ versus control, unpaired two-tailed $t$-test. Enn.n, embryonic day; Heps, hepatocytes; HCC, hepatocellular carcinoma; PT, portal tissue. 
of CK19 and SOX-9 appeared in cultured hepatocytes; expression of SOX-9 was induced earlier, being apparent already in spheroidal cultures (Figure 2A). Compatible with these findings, immunocytochemical analysis revealed a marked reduction of HNF- $4 \alpha$ and the emergence of CK19 and SOX-9 in cultured hepatocytes (Figure 2B).

\section{Emergence of Hepatocyte-Derived Bile Ductular Structures in the Ductular Reaction in Liver Repopulation Experiments}

To evaluate the transdifferentiation capacity of mature hepatocytes in vivo, we then performed lineage-tracing experiments using a liver repopulation model (Figure 3A). Transplanted $\beta-\mathrm{gal}^{+}$Alb-Cre $\times$ROSA26R hepatocytes formed colonies of various sizes in the partially hepatectomized liver of retrorsine-treated mice, in which the proliferation of host hepatocytes was suppressed but that of transplanted hepatocytes was stimulated (Figure 3B). In a setting of mild to moderate liver injury, scattered areas of ductular reaction were observed in which a small population of increased ductules were $\beta$-gal ${ }^{+}$(Figure 3B). When similarly treated mice were subjected to further liver injury induced by a DDC diet or $\mathrm{CCl}_{4}$, an extensive ductular reaction occurred; a number of $\beta$-gal ${ }^{+}$ducts or ductules were found, especially proximal to the colonies of transplanted
A

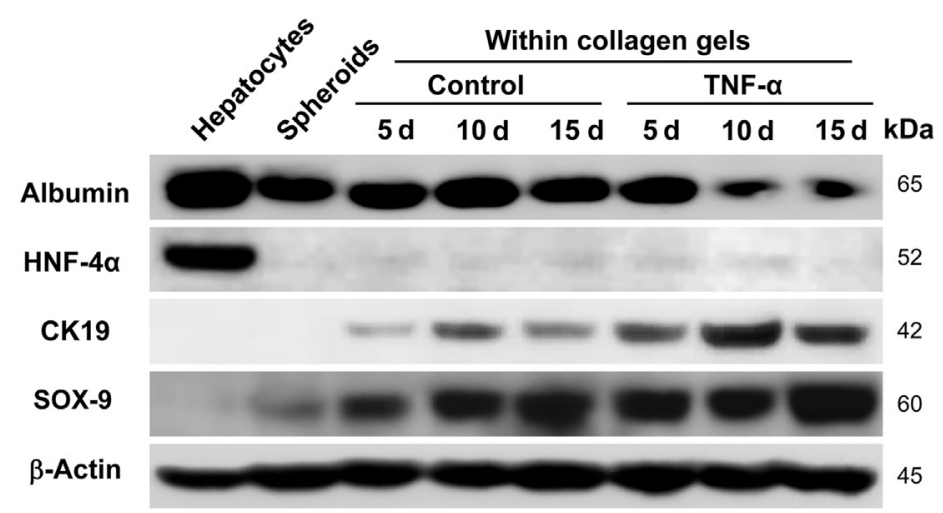

Figure 2 Loss of hepatocytespecific protein expression and the emergence of bile duct-specific protein expression in mouse hepatocytes in collagen gel culture. A: Western blotting analysis of proteins specific for hepatocytes (albumin and HNF-4 $\alpha$ ) and bile ducts or ductules (CK19 and SOX-9) in freshly isolated and cultured hepatocytes. B: H\&E staining and immunocytochemistry for HNF- $4 \alpha$, CK19, and SOX-9 of freshly isolated and cultured hepatocytes. Scale bar $=$ $20 \mu \mathrm{m}$. H\&E, hematoxylin and eosin.

B

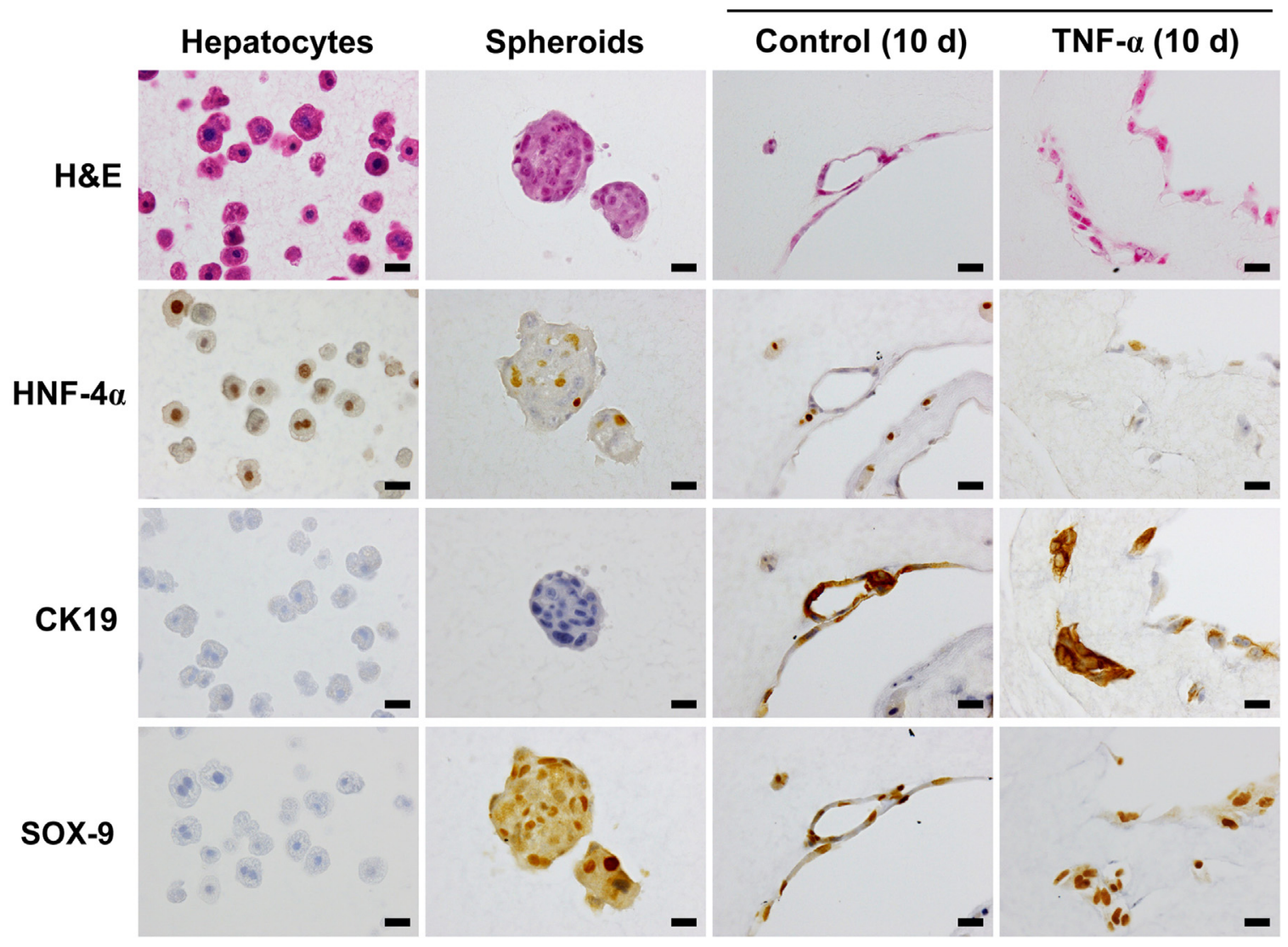




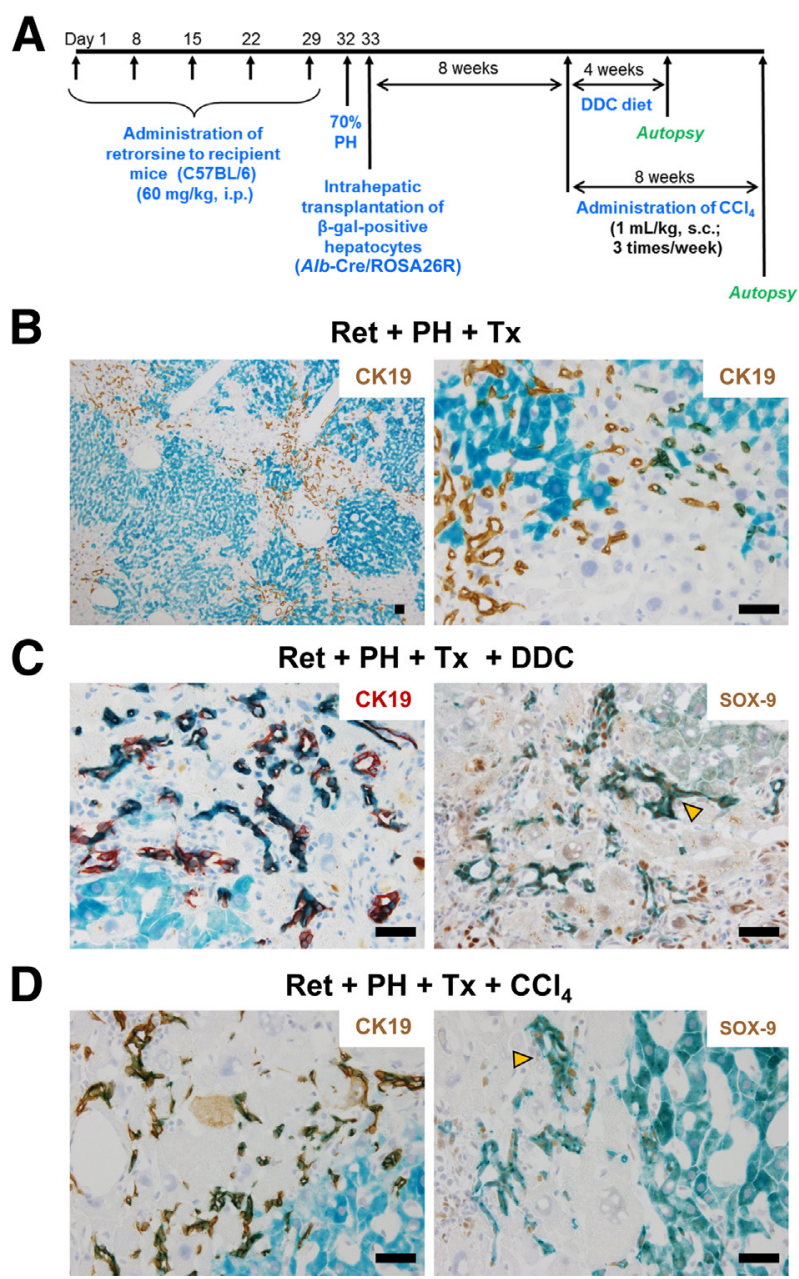

Figure 3 Bile ductular transdifferentiation of $A l b$-Cre $\times$ ROSA26R mouse hepatocytes that were transplanted and repopulated in wildtype mouse liver. A: Schematic of the lineage tracing experiments using a liver repopulation model. B-D: Combined X-Gal histochemistry and immunohistochemistry for CK19 or S0X-9 in liver at 8 weeks after hepatocyte transplantation (B) and subsequent subjection to liver injury induced by a DDC diet for 4 weeks (C) or by $\mathrm{CCl}_{4}$ treatment for 8 weeks (D). Scale bar $=40 \mu \mathrm{m}$. DDC, 3,5diethoxycarbonyl-1,4-dihydrocollidine; $\mathrm{PH}$, partial hepatectomy; Ret, retrorsine; Tx, transplantation; X-Gal, 5-bromo-4-chloro-3-indolyl- $\beta$-Dgalactopyranoside.

$\beta$-gal ${ }^{+}$hepatocytes, which were also positive for SOX-9 (Figure 3, C and D).

\section{Relative Contribution of Hepatocyte-Derived Bile Ductules in the Ductular Reaction Assessed in a Hepatocyte-Specific Gene Targeting System}

These in vitro and in vivo experiments clearly demonstrated that mature hepatocytes possess the capacity to differentiate into bile duct/ductular cells in response to microenvironmental changes. However, the relative contribution of the proliferation of bile ducts or ductules and the transdifferentiation of hepatocytes in the ductular reaction remained unknown. To examine this, it was necessary to induce injury in intact liver in which the resident hepatocytes were specifically and permanently labeled. We therefore applied a poly(I:C)-inducible gene targeting system (MxICre $\times$ ROSA26R) ${ }^{18,24,25}$ We confirmed the efficient and specific labeling of hepatocytes, which almost entirely spared the bile duct/ductular cells (Figures 4 and 5A) and other nonparenchymal cells (Figures 4 and 5B), on the completion of repeated administration of poly(I:C). However, after a long time (15 months) had elapsed since labeling, a small but significant increase in $\beta$-gal ${ }^{+}$duct/ductular cells occurred (Figure 5A), reaching $4.2 \%$ of the $\mathrm{CK} 19^{+}$ductular cells (Figure 5, B and C), which suggested involvement of periportal hepatocytes in the normal homeostasis of duct/ductular cells.

We then examined the cellular origins of ductular reaction in the periportal area induced by a DDC diet or DAPM. These toxic agents significantly increased the number of ductular structures composed of $\mathrm{CK} 19^{+}$cells, which were slightly larger than normal bile ductular cells (Figure 5A). The reactive bile ductules contained a small number of $\beta$-gal ${ }^{+}$cells (Figure 5, A and B), which were estimated to make up $1.9 \%$ and $4.7 \%$ of the $\mathrm{CK} 19^{+}$ductular cells in the liver of DDC diet-fed and DAPM-treated mice, respectively (Figure 5C). The increased ductular structures induced by BDL also contained a small number of $\beta-\mathrm{gal}^{+}$cells (Supplemental Figure S4). These findings demonstrated that mature hepatocytes also contribute, although not extensively, to the periportal ductular reaction due to various injuries.

We also evaluated the cellular origins of ductular reactions in the centrilobular area, where no bile ductular cells are present. Chronic administration of $\mathrm{CCl}_{4}$ or TAA selectively damaged centrilobular hepatocytes, causing inflammation,

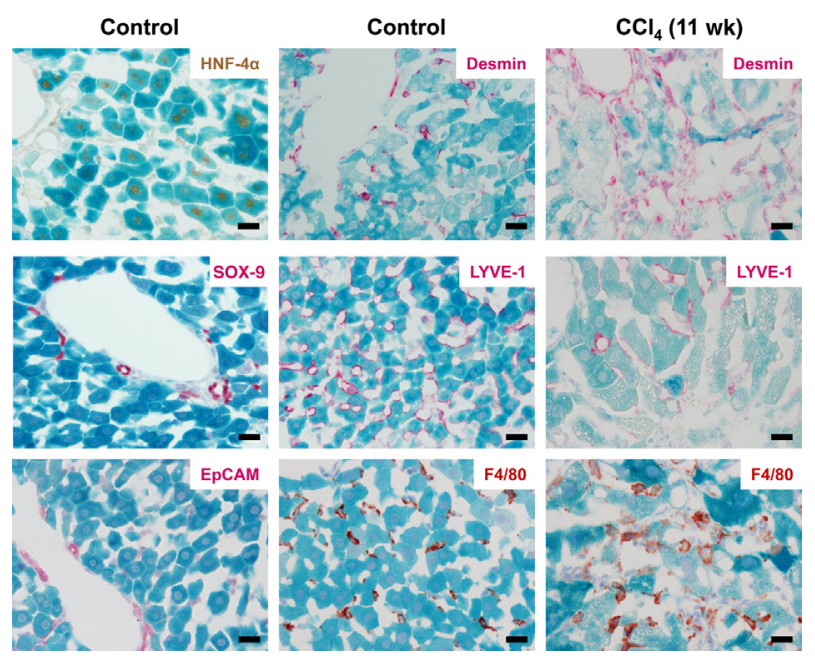

Figure 4 Hepatocyte-specific $\beta$-gal labeling in Mx1-Cre $\times$ R0SA26R mice after polyinosinic-polycytidylic acid [poly(I:C)] injections in control (intact) liver at 3 days after the last poly(I:C) injection and in liver treated with $\mathrm{CCl}_{4}$ for 11 weeks. Combined X-Gal histochemistry and immunohistochemistry for various liver cell markers: HNF- $4 \alpha$ (hepatocytes; brown); SOX9 and EpCAM (bile duct/ductular cells; red); desmin (stellate cells; red); LYVE-1 (sinusoidal endothelial cells; red); and F4/80 (Kupffer cells; reddish brown). Scale bar $=20 \mu \mathrm{m}$. 


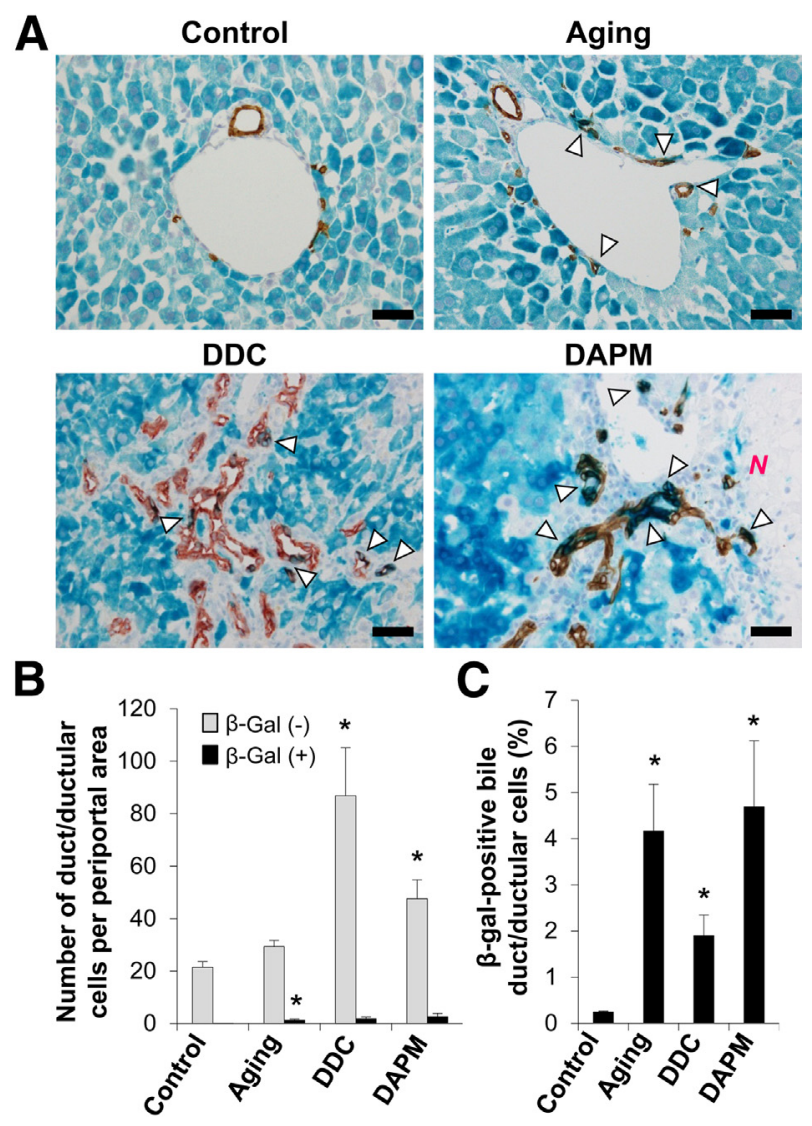

Figure 5 Ductular transdifferentiation of hepatocytes in liver homeostasis and the periportal ductular reaction in a hepatocyte lineage-tracing system using Mx1-Cre $\times$ ROSA26R mice. A: Combined X-gal histochemistry and immunohistochemistry for CK19 in the liver at 3 days (control) and 15 months (aging) after the final poly(I:C) injection and after liver injuries induced by DDC diet or DAPM. $\beta$-Gal ${ }^{+}$bile duct/ductular cells are indicated by arrowheads; note the necrotic $(\mathrm{N})$ area in the DAPM-treated liver. B: The number of $\beta$-gal ${ }^{-}$and $\beta$-gal ${ }^{+}$bile duct/ductular cells in the periportal area. C: The proportion of $\beta$-gal ${ }^{+}$cells in $\mathrm{CK}_{1} 9^{+}$bile duct/ductular cells. Data are expressed as means \pm SEM. $n=3$ (control, aging, and DDC) or $n=4$ (DAPM) mice. ${ }^{*} P<0.05$ versus control, one-way factorial analysis of variance. Scale bar $=40 \mu \mathrm{m}$. DAPM, 4,4'-diaminodiphenylmethane.

fibrosis, and ductular reaction in the centrilobular area (Supplemental Figure S5). Although no hepatic stellate cells, sinusoidal endothelial cells, or Kupffer cells were $\beta-\mathrm{gal}^{+}$in the injured liver (Figure 4), the CK19 ${ }^{+}$ductules in the centrilobular area (zone 3 ) were composed of $\beta-\mathrm{gal}^{+}$and $\beta-\mathrm{gal}^{-}$ cells (Figure 6, A and B). The $\beta$-gal ${ }^{+}$ductules of hepatocyte origin were found mainly in inflamed and fibrosed areas in the vicinity of the central veins, and $\beta$-gal ${ }^{+}$and $\beta$-gal ${ }^{-}$ ductules often were in contact with each other and shared lumens (Figure 6A). The number of ductules containing $\beta$-gal ${ }^{+}$cells per centrilobular area was 4.1 and 1.3 in $\mathrm{CCl}_{4}(20$ weeks) and TAA (21 weeks) injury, respectively (Figure 6B). In the early period of $\mathrm{CCl}_{4}$ injury (8 weeks), $20.6 \%$ of ductular cells were $\beta-\mathrm{gal}^{+}$, but this proportion decreased thereafter as the ductular reaction progressed (Figure 6C). Although TAA induced an extensive ductular reaction, the proportion of $\beta$-gal ${ }^{+}$cells was small (4.3\%) (Figure 6C).
Extensive Remodeling of the Intrahepatic Biliary System in Chronic Liver Injury

Notably, as the centrilobular ductular reaction progressed, the bile ducts or ductules in the portal tract appeared to migrate toward the injured centrilobular area, leaving the portal tract without duct/ductular structures (Figure 6, A and D). The vascular structures in the uninjured area were confirmed to be portal vein branches by retrograde injection of India ink from the portal trunk (Figure 6E). The hepatic arteries, which are usually confined within the portal connective tissue, were often located in the midst of liver lobules, suggesting migration of hepatic arteries toward the centrilobular direction (Figure 6F).

To visualize three-dimensional alterations of the intrahepatic bile duct system in the centrilobular ductular reaction, we retrogradely injected India ink and vermilion ink into the common bile duct and the portal vein trunk, respectively, of control and $\mathrm{CCl}_{4}$-injured liver, and then treated fixed liver slices with a clearing reagent until they became transparent. In control liver, India ink was accumulated in bile ducts or ductules around the portal veins; the portal veins contained vermilion ink (Figure 7A). By contrast, in $\mathrm{CCl}_{4}$-injured liver, pigment-containing bile ducts or ductules were present as extensive networks within the lobules, most of them reaching the centrilobular area (Figure 7A). In $\mathrm{CCl}_{4}$-injured liver of poly(I:C)-treated $M x l$-Cre $\times$ ROSA26R mice, India ink pigments infused into the common bile duct were found inside the aberrantly located bile ducts or ductules, some of which were composed of $\beta$-gal ${ }^{+}$and $\beta$-gal ${ }^{-}$cells, indicating that the biliary system connection was maintained (Figure 7, B and C). Furthermore, examination of serial sections revealed the actual anatomical connection between periportal bile ducts and centrilobular bile ducts or ductules (Figure 7C).

To elucidate the role of cell proliferation in the increase of ductular structures in centrilobular liver injury, we performed double immunostaining for phosphorylated histone H3 (p-HH3) and CK19 on $\beta$-gal-stained sections and counted proliferating cells in $\beta$-gal ${ }^{-}$and $\beta$-gal ${ }^{+}$ducts or ductules. Although $\mathrm{p}-\mathrm{HH}^{+}$cells were occasionally found in $\beta$-gal ${ }^{-}$ducts or ductules in $\mathrm{CCl}_{4}$ and TAA injured tissue, small $\beta-\mathrm{gal}^{+}$ductules barely demonstrated $\mathrm{p}-\mathrm{HH} 3$ positivity (Figure 8A). Quantification revealed that $\mathrm{p}-\mathrm{HH}^{+}$cells made up $0.67 \%$ and $1.66 \%$ of the $\beta$-gal ${ }^{-}$ductular cells in $\mathrm{CCl}_{4}$ and TAA injuries, respectively (Figure 8B). By contrast, $\beta$-gal ${ }^{+}$ductules contained only $0.01 \%$ of $\mathrm{p}-\mathrm{HH} 3^{+}$ cells in the presence of $\mathrm{CCl}_{4}$ injury, and no positive cells were detected in the presence of TAA injury (Figure 8B).

These results suggest that extensive tissue remodeling processes occur during migration of ductular cells. We have previously identified various proteins involved in tissue remodeling whose mRNA expression was increased in $\mathrm{CCl}_{4}$-induced cirrhosis by cDNA microarray analysis (X.C. and Y.N., unpublished observations). We therefore performed RT-qPCR analysis for mRNA expression of such proteins, comparing control and $\mathrm{CCl}_{4}$-induced or 
A
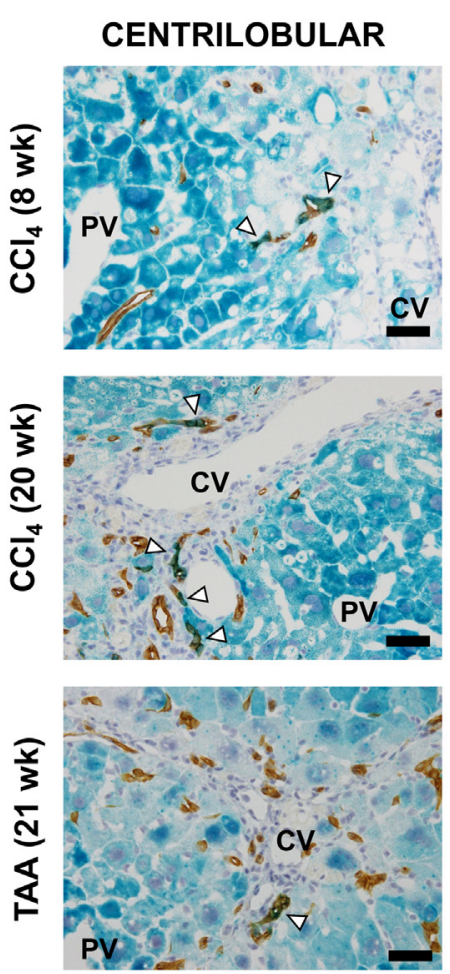

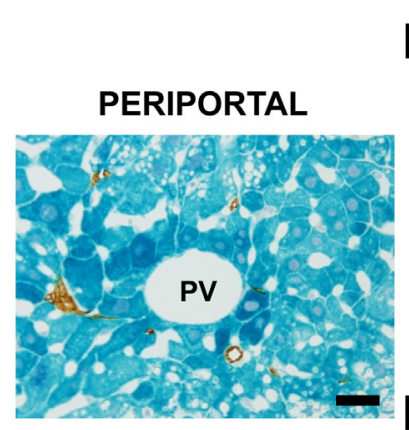

B
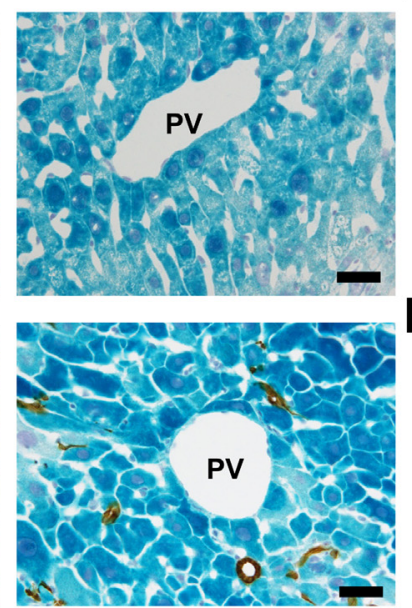

\section{$\mathbf{F}$}

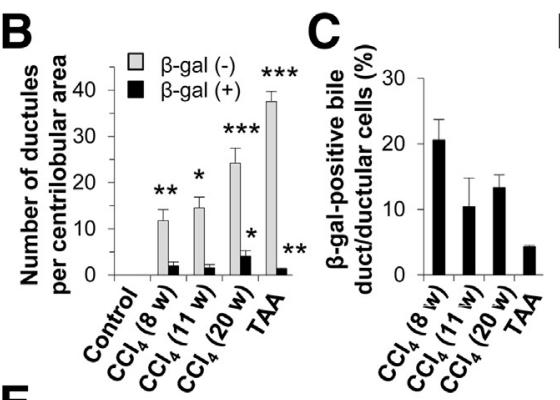

D
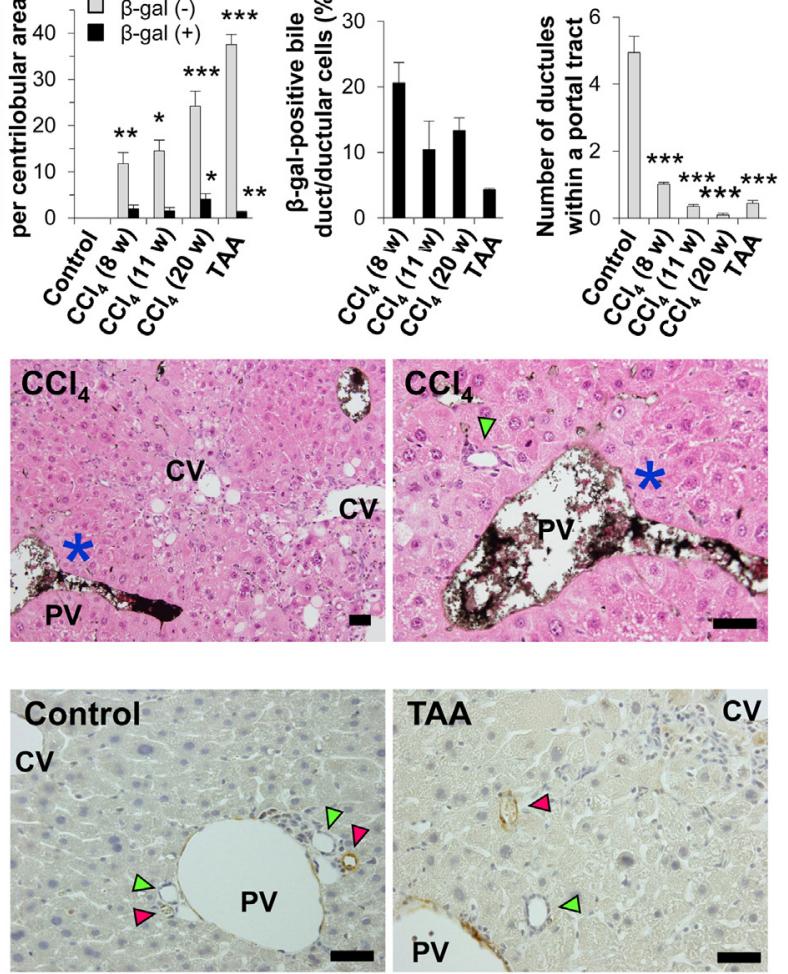

Figure 6 Contribution of the ductular transdifferentiation of hepatocytes and migration of existing bile duct/ductular cells in the centrilobular ductular reaction in a hepatocyte lineage-tracing system using Mx1-Cre $\times$ ROSA26R mice. A: Combined X-Gal histochemistry and immunohistochemistry for CK19 in liver treated with $\mathrm{CCl}_{4}$ (for 8 and 20 weeks) or TAA (21 weeks) in the centrilobular (zone 3 ) and periportal (zone 1 ) areas. $\beta$-Gal ${ }^{+}$bile duct/ductular cells are indicated by arrowheads. B: The number of $\beta$-gal ${ }^{-}$and $\beta$-gal ${ }^{+}$bile duct/ductular cells in the centrilobular area. C: The proportion of $\beta$-gal ${ }^{+}$cells in $\mathrm{CK}_{1} 9^{+}$bile duct/ductular cells in the centrilobular area. D: The number of duct/ductular structures within a portal tract. E: Visualization of portal vein branches by retrograde injection of India ink through the portal vein in $\mathrm{CCl}_{4}$-treated liver (20 weeks). The same specimen is shown at two magnifications, and in each the portal tract is indicated by an asterisk. An interlobular bile duct (arrowhead) apparently migrated from the portal tract. H\&E stain. F: Immunohistochemistry for $\alpha$-smooth muscle actin in intact and TAAtreated (21 weeks) liver. Note interlobular bile ducts (green arrowheads) and hepatic arteries (red arrowheads). Data are expressed as means \pm SEM. $n=3$ mice $\left(\mathrm{CCl}_{4}, 8\right.$ and 11 weeks; TAA) or $n=4$ mice $\left(\mathrm{CCl}_{4}, 20\right.$ weeks). ${ }^{*} P<0.05,{ }^{*} P<0.01$, and ${ }^{* * *} P<0.001$ versus control, one-way factorial analysis of variance. $\mathrm{CV}$, central veins; PV, portal veins. Scale bar $=40 \mu \mathrm{m}$.

TAA-induced cirrhosis. There were significant increases in S100a4, Mmp2, and Timpl mRNA in the injured liver (Figure 8C).

\section{Discussion}

Although some investigators have proposed that the phenotype of hepatocytes is fixed once they are terminally differentiated, ${ }^{26}$ this notion has been challenged by recent studies demonstrating phenotypic plasticity of hepatocytes. ${ }^{9,11,16}$ With the present study, as an extension of our previous work showing transdifferentiation of rat hepatocytes into bile $\mathrm{duct} /$ ductular cells in a collagen gel matrix, ${ }^{8-10,13}$ we have demonstrated that mouse hepatocytes also transform into ductular cells in vitro, especially when TNF- $\alpha$ is present in the culture medium. Ductular differentiation of mouse hepatocytes was not associated with the expression of Dlkl mRNA, which was present in fetal liver and in some hepatocellular carcinomas. Thus, the ductular transformation of mouse hepatocytes within collagen gels could be interpreted as resulting from the process of transdifferentiation rather than dedifferentiation.

The idea that hepatocytes can transform into ductular cells in vivo has been a subject of intense debate. ${ }^{26-28}$ To look for further evidence of transdifferentiation, we isolated centrilobular hepatocytes (permanently labeled by $\beta$-gal) from Alb-Cre $\times$ ROSA26R mice and transplanted them into the liver of wild-type mice. We previously demonstrated that centrilobular and periportal hepatocytes of rat possess nearly identical capacities for ductular differentiation in vitro. ${ }^{9}$ Our present results demonstrated that hepatocytes can transform into bile duct/ductular cells in vivo. The transformation was readily observed at the periphery of the repopulated hepatocytic colonies, and it was markedly enhanced by chronic $\mathrm{CCl}_{4}$ administration or a DDC diet. The robust ductular reaction was also closely associated with inflammation induced by retrorsine and a partial hepatectomy and was further augmented by additional injurious stimuli. The inflammatory background might promote ductular transdifferentiation through an increase in extracellular matrices and various inflammatory 
A
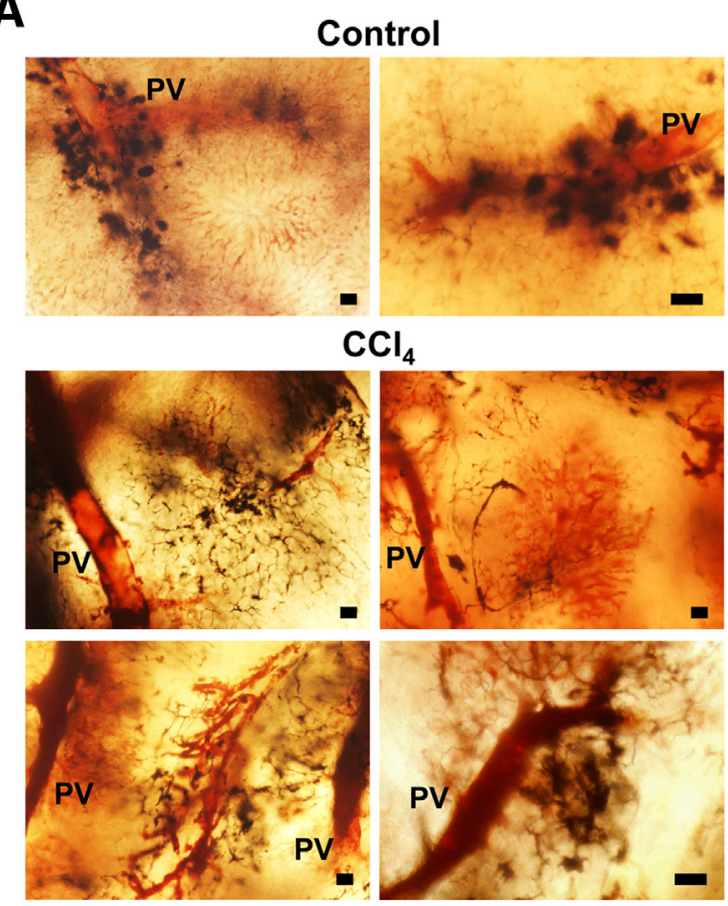

C
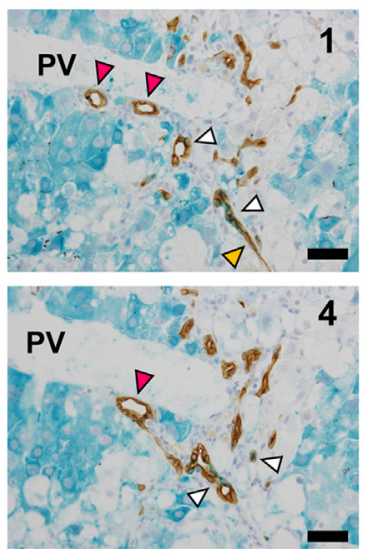

B
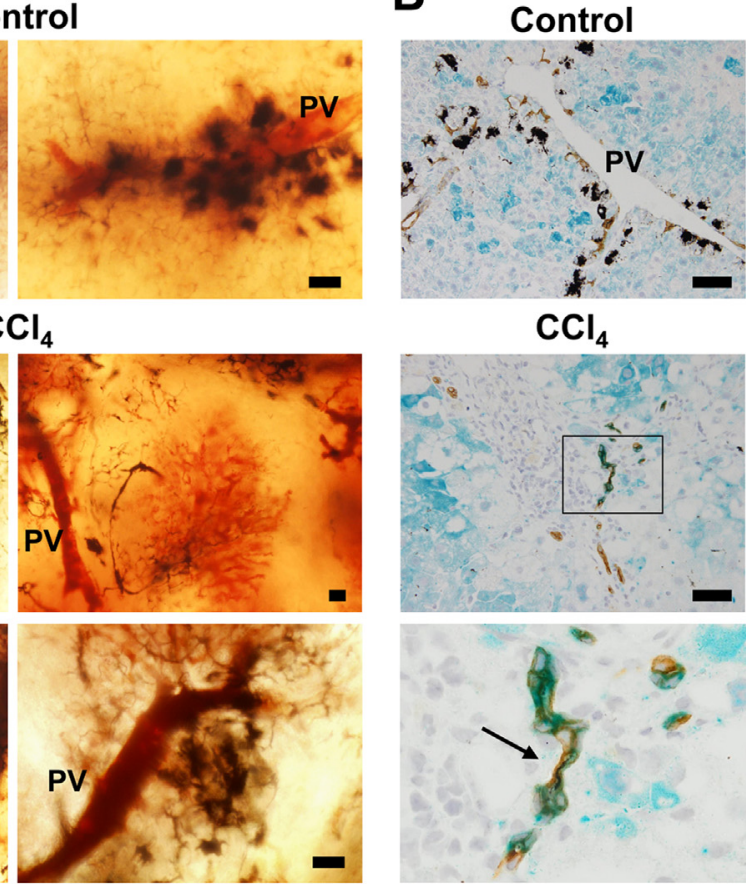

$\mathrm{CCl}_{4}$
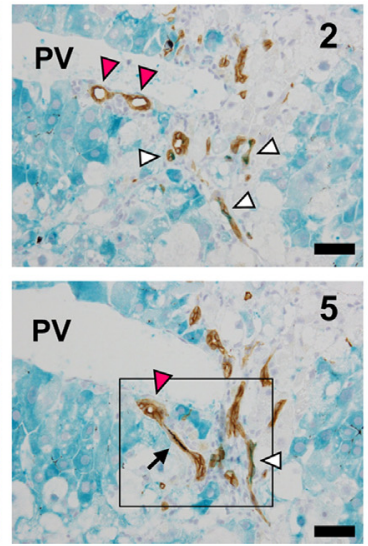
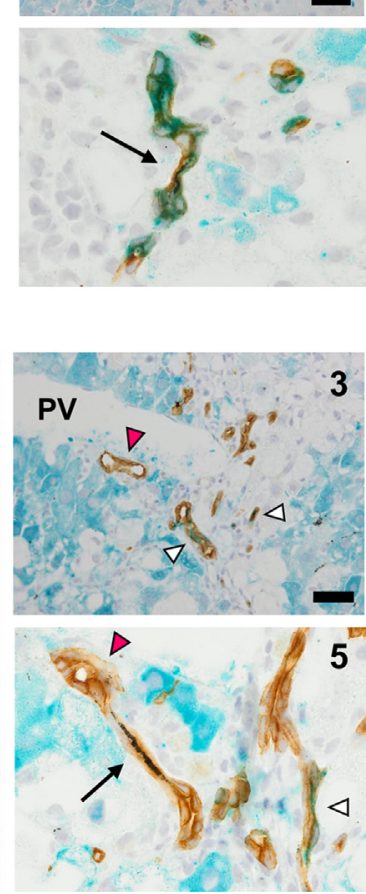

Figure 7 The three-dimensional structures of the centrilobular ductular reaction and its connection to the existing biliary system. A: Threedimensional visualization of the bile ducts or ductules by retrograde injection of India ink and vermilion ink through the common bile duct and the portal vein trunk, respectively, in intact (control) and $\mathrm{CCl}_{4}$-treated (20 weeks) liver. B and C: Combined X-Gal histochemistry and immunohistochemistry for CK19 of the liver in a hepatocyte lineage-tracing system, using Mx1-Cre $\times$ ROSA26R mice, in which India ink was injected through the common bile duct. B: Intact (control) and $\mathrm{CCl}_{4}-$ treated (20 weeks) liver. The boxed area in the middle panel is shown in detail with a $100 \times$ oil immersion objective in the bottom panel. Note the presence of India ink pigments (arrow) inside the lumen of the $\mathrm{CCl}_{4}$-induced aberrant bile ductule, which is composed of $\beta$-gal ${ }^{+}$and $\beta-\mathrm{gal}^{-}$cells. C: Five serial sections ( $4 \mu \mathrm{m}$ thick) of $\mathrm{CCl}_{4}$-treated ( 20 weeks) liver. The periportal bile ducts (red arrowheads) and the centrilobular bile ductules (yellow arrowhead) are continuous. $\beta-\mathrm{Gal}^{+}$bile duct/ ductular cells are indicated by white arrowheads. The boxed area (section 5) is shown in detail with a $100 \times$ oil immersion objective in the panel to the right. Note intraluminal India ink pigments (arrow). Scale bar $=40 \mu \mathrm{m}$. cytokines, including TNF- $\alpha$. Interestingly, some hepatocytes near the ductular reaction expressed SOX-9 but not CK19, which could represent an intermediate hepatobiliary phenotype. $^{29}$

No definitive functional significance for the ductular transdifferentiation of hepatocytes has been elucidated. However, it is noteworthy that similar phenomena occur during the development of the intrahepatic bile duct system in which albumin-producing hepatoblasts form bile duct/ductular cells along the developing portal connective tissue. ${ }^{30}$ Our present findings strongly suggest that transdifferentiation can participate in homeostasis of the biliary system in intact liver and in ductular reaction in various liver diseases. We speculate that this cellular response might have a crucial role in maintaining and establishing the connection of the bile conduit system between hepatocytes and bile ductular cells.

Hepatocytes and bile ducts or ductules can participate in ductular reaction. The liver repopulation model is not suitable for analyzing the relative contribution of intrinsic hepatocytes and bile ducts or ductules, because repopulation by the transplanted hepatocytes would affect the structures of the host hepatic lobules and retrorsine administration and a partial hepatectomy would alter the proliferative activity of the host cells. In the present study, we used Mxl-Cre $\times$ ROSA26R mice, in which hepatocytes can be labeled efficiently and specifically by poly(I:C) administration without affecting liver physiology. Some of the bile ductules contained cells of hepatocyte origin (ie, $\beta$ - $\mathrm{gal}^{+}$) in the presence of periportal and centrilobular liver injuries, although they constituted relatively small fractions of the bile ducts or ductules in the injured areas. In an efficient hepatocyte-lineage tracing system in mouse, in which an adeno-associated virus vector was applied, Malato et $\mathrm{al}^{15}$ reported that the transformation did not occur with injuries induced by acute or chronic $\mathrm{CCl}_{4}$ administrations, BDL, or DDC diet. By contrast, in a more recent 


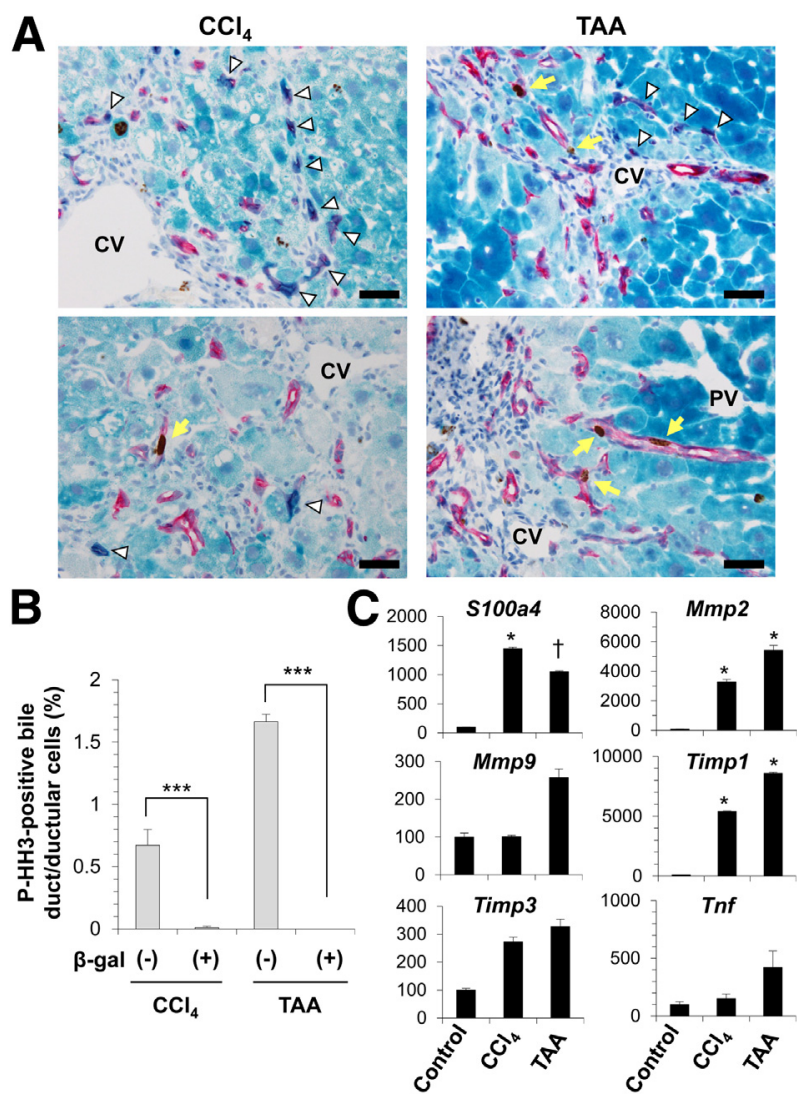

Figure 8 Migration and proliferation of bile ducts or ductules in the centrilobular ductular reaction. A: Triple staining of X-Gal, CK19 (red), and $\mathrm{p}-\mathrm{HH} 3$ (brown) in the liver of $\mathrm{CCl}_{4}(20$ weeks; $n=4)$ or TAA $(n=3)$ in a hepatocyte lineage-tracing system using $M \times 1-\mathrm{Cre} \times$ ROSA26R mice. $\beta-\mathrm{Gal}^{+}$ bile ducts or ductules are indicated by arrowheads; $\mathrm{p}-\mathrm{HH}^{+}$bile ducts or ductules are indicated by arrows. B: The percentage of $\mathrm{p}-\mathrm{HH}^{+}$cells, indicative of proliferation, in $\beta$-gal ${ }^{-}$and $\beta$-gal ${ }^{+}$bile ducts or ductules. C: RT-qPCR analysis for relative mRNA expression of S100a4, Mmp2, Mmp9, Timp1, Timp3, and Tnfa in the liver of control $(n=4), \mathrm{CCl}_{4}-$ treated (24 weeks; $n=4$ ), and TAA-treated (24 weeks; $n=5$ ) animals. Data are expressed as means \pm SEM. ${ }^{* * *} P<0.001$, one-way factorial analysis of variance (B). ${ }^{*} P<0.05 ;{ }^{\dagger} P<0.005$ versus control, unpaired two-tailed $t$-test (C). Scale bar $=40 \mu \mathrm{m}$.

study using a similar adeno-associated virus-mediated hepatocyte-lineage tracing system, Yanger et $\mathrm{al}^{16}$ showed that some of the new ductules induced by a DDC diet, and to a lesser degree those induced by BDL, were derived from hepatocytes. Although the reason for the discrepancy between these studies is unclear, our results are in accord with those of Yanger et al. ${ }^{16}$ Using combinations of tamoxifeninducible Cre and ROSA26R systems, which label albumin-positive cells or CK19 ${ }^{+}$cells, Sekiya and Suzuki ${ }^{17}$ reported that almost all of the $\mathrm{CK} 19^{+}$ductular cells that appeared in the liver of the mice treated with TAA were of hepatocyte origin and not of bile-duct origin. Our present findings, however, indicate that cells participating in a centrilobular ductular reaction induced by TAA (or by $\mathrm{CCl}_{4}$ ) are more complex and include at least transdifferentiated hepatocytes and bile ductules that have migrated from the portal area.
Although less extensively described than periportal ductular reaction, centrilobular ductular reaction is also involved in various human liver diseases. Severe congestion of the liver has been associated with this reaction, which is also known as reversed lobulation. ${ }^{31}$ Desmet $^{6}$ suggested that ductular cells in the centrilobular area might originate from hepatocytes in response to the hypoxic conditions. Centrilobular hepatocyte injury and fibrosis associated with ductular reaction are also characteristics of alcoholic liver disease and nonalcoholic steatohepatitis. $^{7,32}$ One of the most unexpected findings from the present study was that the liver showed extensive tissue remodeling in chronic centrilobular liver injury induced by repeated administration of $\mathrm{CCl}_{4}$ or TAA. Our results show for the first time that periportal ductular cells and interlobular bile ducts can proliferate and migrate to the centrilobular area and establish the connection between the transdifferentiated hepatocytes. This tissue remodeling also involves intralobular migration of hepatic arteries, which are known to play important roles in the circulation of bile ducts or ductules. Provocatively, hepatic arterial deprivation has been reported to induce adaptive proliferation of bile duct/ductular cells. ${ }^{33}$ It is of note that similar migration of hepatic arteries (centrizonal arteries) has been observed in patients with nonalcoholic steatohepatitis,

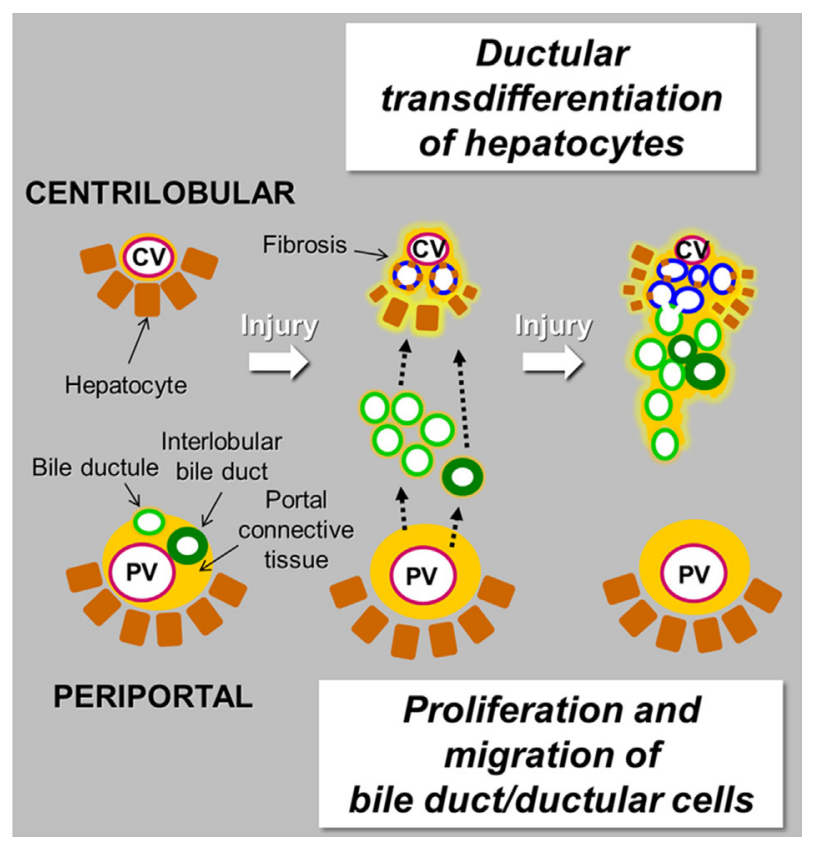

Figure 9 Schematic representation of two distinct origins for duct/ ductular cells in the centrilobular ductular reaction. The present findings demonstrate the phenotypic plasticity of mature hepatocytes, as well as the extensive remodeling capacity of the existing bile duct system. Centrilobular hepatocytes transdifferentiate into bile duct/ductular cells in response to microenvironmental changes (eg, chronic inflammation and fibrosis) induced by chronic liver injury. Concomitantly, bile duct/ductular cells, which were originally located in the portal tract, proliferate and migrate toward the injured area, eventually establishing connections with transdifferentiated hepatocytes. 
especially in the presence of advanced centrilobular fibrosis and ductular reaction. ${ }^{34}$

The extensive tissue remodeling in the presence of chronic centrilobular liver injuries might be related to the changes in the regulatory mechanisms of extracellular matrices. Biliary remodeling during liver regeneration is associated with an increase in S100-A4, which induces the expression of MMPs. ${ }^{35}$ In the present study, RT-qPCR analysis comparing control and $\mathrm{CCl}_{4}$-induced or TAAinduced cirrhosis demonstrated significant increases in the mRNA of Mmp2 and Timp1, as well as of S100a4. Furthermore, soluble factors, such as inflammatory cytokines released from the inflamed centrilobular area might be involved in the remodeling process. ${ }^{10,36}$

In conclusion, our present results demonstrate that marked hepatic lobular remodeling occurs after chronic centrilobular injury, involving both ductular transdifferentiation of hepatocytes and proliferation and migration of bile duct/ductular cells (Figure 9). Because ductular transdifferentiation of hepatocytes has been suggested to be reversible, depending on the microenvironment, ${ }^{13}$ clear recognition of the presence of bile ductules of different cellular origins in the injured liver should be important for a more precise understanding of the pathology of chronic liver diseases and the development of new therapeutic interventions.

\section{Acknowledgments}

We thank Kiyonaga Fujii (Asahikawa Medical University), Takako Ooshio (Asahikawa Medical University), and all our former colleagues of the Department of Pathology at Akita University Graduate School of Medicine for their helpful discussions and criticisms, and Ema Yamatomi and Hiroko Chiba (Asahikawa Medical University) for excellent secretarial assistance.

\section{Supplemental Data}

Supplemental material for this article can be found at http://dx.doi.org/10.1016/j.ajpath.2014.07.005.

\section{References}

1. Desmet V, Roskams T, Van Eyken P: Ductular reaction in the liver Pathol Res Pract 1995, 191:513-524

2. Alvaro D, Mancino MG, Glaser S, Gaudio E, Marzioni M, Francis H, Alpini G: Proliferating cholangiocytes: a neuroendocrine compartment in the diseased liver. Gastroenterology 2007, 132:415-431

3. Clouston AD, Powell EE, Walsh MJ, Richardson MM, Demetris AJ, Jonsson JR: Fibrosis correlates with a ductular reaction in hepatitis C: roles of impaired replication, progenitor cells and steatosis. Hepatology 2005, 41:809-818

4. Lowes KN, Croager EJ, Olynyk JK, Abraham LJ, Yeoh GC: Oval cellmediated liver regeneration: role of cytokines and growth factors. J Gastroenterol Hepatol 2003, 18:4-12

5. Gouw AS, Clouston AD, Theise ND: Ductular reactions in human liver: diversity at the interface. Hepatology 2011, 54:1853-1863
6. Desmet VJ: Ductal plates in hepatic ductular reactions. Hypothesis and implications. I. Types of ductular reaction reconsidered. Virchows Arch 2011, 458:251-259

7. Van Eyken P, Sciot R, Desmet VJ: A cytokeratin immunohistochemical study of alcoholic liver disease: evidence that hepatocytes can express 'bile duct-type' cytokeratins. Histopathology 1988, 13: 605-617

8. Nishikawa Y, Tokusashi Y, Kadohama T, Nishimori H, Ogawa K: Hepatocytic cells form bile duct-like structures within a threedimensional collagen gel matrix. Exp Cell Res 1996, 223:357-371

9. Nishikawa Y, Doi Y, Watanabe H, Tokairin T, Omori Y, Su M, Yoshioka T, Enomoto K: Transdifferentiation of mature rat hepatocytes into bile duct-like cells in vitro. Am J Pathol 2005, 166: 1077-1088

10. Nishikawa Y, Sone M, Nagahama Y, Kumagai E, Doi Y, Omori Y, Yoshioka T, Tokairin T, Yoshida M, Yamamoto Y, Ito A, Sugiyama T, Enomoto K: Tumor necrosis factor-alpha promotes bile ductular transdifferentiation of mature rat hepatocytes in vitro. J Cell Biochem 2013, 114:831-843

11. Michalopoulos GK, Barua L, Bowen WC: Transdifferentiation of rat hepatocytes into biliary cells after bile duct ligation and toxic biliary injury. Hepatology 2005, 41:535-544

12. Limaye PB, Bowen WC, Orr AV, Luo J, Tseng GC, Michalopoulos GK: Mechanisms of hepatocyte growth factor-mediated and epidermal growth factor-mediated signaling in transdifferentiation of rat hepatocytes to biliary epithelium. Hepatology 2008, 47:1702-1713

13. Sone M, Nishikawa Y, Nagahama Y, Kumagai E, Doi Y, Omori Y, Yoshioka T, Tokairin T, Yoshida M, Sugiyama T, Enomoto K: Recovery of mature hepatocytic phenotype following bile ductular transdifferentiation of rat hepatocytes in vitro. Am J Pathol 2012, 181: 2094-2104

14. Wang X, Foster M, Al-Dhalimy M, Lagasse E, Finegold M, Grompe M: The origin and liver repopulating capacity of murine oval cells. Proc Natl Acad Sci USA 2003, 100(Suppl 1):11881-11888

15. Malato Y, Naqvi S, Schürmann N, Ng R, Wang B, Zape J, Kay MA, Grimm D, Willenbring H: Fate tracing of mature hepatocytes in mouse liver homeostasis and regeneration. J Clin Invest 2011, 121: $4850-4860$

16. Yanger K, Zong Y, Maggs LR, Shapira SN, Maddipati R, Aiello NM, Thung SN, Wells RG, Greenbaum LE, Stanger BZ: Robust cellular reprogramming occurs spontaneously during liver regeneration [Erratum appeared in Genes Dev 2013, 27:1537]. Genes Dev 2013, 27 : 719-724

17. Sekiya S, Suzuki A: Intrahepatic cholangiocarcinoma can arise from Notch-mediated conversion of hepatocytes. J Clin Invest 2012, 122: 3914-3918

18. Kühn R, Schwenk F, Aguet M, Rajewsky K: Inducible gene targeting in mice. Science 1995, 269:1427-1429

19. Soriano P: Generalized lacZ expression with the ROSA26 Cre reporter strain. Nat Genet 1999, 21:70-71

20. National Research Council: Guide for the Care and Use of Laboratory Animals. ed 8. Washington, DC, National Academies Press, 2011

21. Lindros KO, Penttilä KE: Digitonin-collagenase perfusion for efficient separation of periportal or perivenous hepatocytes. Biochem J 1985, 228:757-760

22. Nishikawa Y: Transdifferentiation of mature hepatocytes into bile duct/ductule cells within a collagen gel matrix. Methods Mol Biol 2012, 826:153-160

23. Guo D, Fu T, Nelson JA, Superina RA, Soriano HE: Liver repopulation after cell transplantation in mice treated with retrorsine and carbon tetrachloride. Transplantation 2002, 73:1818-1824

24. Yamaji S, Zhang M, Zhang J, Endo Y, Bibikova E, Goff SP, Cang Y: Hepatocyte-specific deletion of DDB1 induces liver regeneration and tumorigenesis. Proc Natl Acad Sci USA 2010, 107:22237-22242

25. Tanimizu N, Nishikawa Y, Ichinohe N, Akiyama H, Mitaka T: Sry HMG box protein 9-positive (Sox9+) epithelial cell adhesion molecule-negative (EpCAM-) biphenotypic cells derived from 
hepatocytes are involved in mouse liver regeneration. J Biol Chem 2014, 289:7589-7598

26. Duncan AW, Dorrell C, Grompe M: Stem cells and liver regeneration. Gastroenterology 2009, 137:466-481

27. Michalopoulos GK: Liver regeneration: alternative epithelial pathways. Int J Biochem Cell Biol 2011, 43:173-179

28. Yanger K, Stanger BZ: Facultative stem cells in liver and pancreas: fact and fancy. Dev Dyn 2011, 240:521-529

29. Ziol M, Nault JC, Aout M, Barget N, Tepper M, Martin A, Trinchet JC, Ganne-Carrié N, Vicaut E, Beaugrand M, N'Kontchou G: Intermediate hepatobiliary cells predict an increased risk of hepatocarcinogenesis in patients with hepatitis $\mathrm{C}$ virus-related cirrhosis. Gastroenterology 2010, 139:335-343

30. Shiojiri N: Development and differentiation of bile ducts in the mammalian liver. Microsc Res Tech 1997, 39:328-335

31. Tanaka M, Wanless IR: Pathology of the liver in Budd-Chiari syndrome: portal vein thrombosis and the histogenesis of veno-centric cirrhosis, veno-portal cirrhosis, and large regenerative nodules. Hepatology 1998, 27:488-496
32. Lefkowitch JH: Scheuer's Liver Biopsy Interpretation, ed 8. Philadelphia, Saunders, 2010, pp 93-114

33. Beaussier M, Wendum D, Fouassier L, Rey C, Barbu V, Lasnier E, Lienhart A, Scoazec JY, Rosmorduc O, Housset C: Adaptative bile duct proliferative response in experimental bile duct ischemia. $\mathrm{J}$ Hepatol 2005, 42:257-265

34. Gill RM, Belt P, Wilson L, Bass NM, Ferrell LD: Centrizonal arteries and microvessels in nonalcoholic steatohepatitis. Am J Surg Pathol 2011, 35:1400-1404

35. Meng F, Francis H, Glaser S, Han Y, DeMorrow S, Stokes A, Staloch D, Venter J, White M, Ueno Y, Reid LM, Alpini G: Role of stem cell factor and granulocyte colony-stimulating factor in remodeling during liver regeneration. Hepatology 2012, 55: 209-221

36. Tarrats N, Moles A, Morales A, García-Ruiz C, FernándezCheca JC, Marí M: Critical role of tumor necrosis factor receptor 1 , but not 2 , in hepatic stellate cell proliferation, extracellular matrix remodeling, and liver fibrogenesis. Hepatology 2011, 54: $319-327$ 